\title{
The Prevalence of Chronic Kidney Disease in a Primary Care Setting: A Swiss Cross-Sectional Study
}

\author{
Yuki Tomonaga ${ }^{1 *}$, Lorenz Risch ${ }^{2,3}$, Thomas D. Szucs ${ }^{4}$, Patrice M. Ambuehl ${ }^{5}$ \\ 1 Institute of Social and Preventive Medicine, Medical Economics, University of Zurich, Zurich, Switzerland, 2 Labormedizinische Zentren Dr. Risch, Liebefeld, Switzerland, \\ 3 Division of Clinical Biochemistry, Center of Chemistry and Biomedicine Innsbruck, Innsbruck Medical University, Innsbruck, Austria, 4 European Center of Pharmaceutical \\ Medicine, University of Basel, Basel, Switzerland, 5 Stadtspital Waid, Renal Division, Zurich, Switzerland
}

\begin{abstract}
Chronic kidney disease (CKD) often remains clinically silent and therefore undiagnosed until a progressed stage is reached. Our aim was to estimate the prevalence of CKD in a primary care setting in Switzerland. A multicenter, cross-sectional study with randomly selected general practitioners was performed. Adults visiting their general physician's cabinet during defined periods were asked to participate. Baseline information was reported on a questionnaire, urine and blood samples were analyzed in a central laboratory. Renal status was assessed using the Kidney Disease: Improving Global Outcomes (KDIGO) classification. Extrapolation of results to national level was adjusted for age and gender. One thousand individuals (57\% females) with a mean age of $57 \pm 17$ years were included. Overall, $41 \%$ of the patients had normal estimated glomerular filtration rate (eGFR) and albumin creatinine ratio (ACR), whereas $36 \%$ of the subjects had slightly reduced excretory renal function with physiological albuminuria based on normal ACR. Almost one fourth of the subjects (23\%) had either a substantially reduced eGFR or high levels of ACR. About $10 \%$ of the patients had a substantially reduced eGFR of $<60 \mathrm{ml} /$ $\mathrm{min} / 1.73 \mathrm{~m}^{2}$, and $17 \%$ showed relevant proteinuria (ACR $>30 \mathrm{mg} / \mathrm{g}$ creatinine). Extrapolation to national level suggests that about $18 \%$ of primary care patients may suffer from CKD. CKD prevalence in a primary care population is therefore high, and preventive interventions may be advisable, in particular as CKD prevalence is likely to rise over the next decades.
\end{abstract}

Citation: Tomonaga Y, Risch L, Szucs TD, Ambuehl PM (2013) The Prevalence of Chronic Kidney Disease in a Primary Care Setting: A Swiss Cross-Sectional Study. PLoS ONE 8(7): e67848. doi:10.1371/journal.pone.0067848

Editor: Cephas Tagumirwa Musabayane, University of KwaZulu-Natal, South Africa

Received April 3, 2013; Accepted May 21, 2013; Published July 3, 2013

Copyright: (c) 2013 Tomonaga et al. This is an open-access article distributed under the terms of the Creative Commons Attribution License, which permits unrestricted use, distribution, and reproduction in any medium, provided the original author and source are credited.

Funding: The authors gratefully acknowledge support by an unrestricted scientific grant from Abbott AG, Switzerland, providing the reagents for this study (https://www.abbott.ch/). The funders had no role in study design, data collection and analysis, decision to publish, or preparation of the manuscript.

Competing Interests: The authors gratefully acknowledge support by an unrestricted scientific grant from Abbott AG, Switzerland, providing the reagents for this study (https://www.abbott.ch/). However, this does not alter our adherence to all the PLOS ONE policies on sharing data and materials. All other authors declare no competing interests.

*E-mail: yuki.tomonaga@uzh.ch

\section{Introduction}

Chronic kidney disease (CKD), defined as renal damage with persistent and usually progressive deterioration of ultrafiltration, is a worldwide public health problem [1]. Several studies have shown that patients with CKD have increased risk of cardiovascular events and increased risk of death [2-12]. Moreover, the ageing of the population in western countries and the generally increasing rates of obesity, hypertension, and diabetes worldwide suggest that the incidence and prevalence of GKD will rise over the next decades $[13,14]$.

The classification of CKD is mainly based on measured or estimated glomerular filtration rate (GFR). In GKD stages 1 and 2, kidney function is normal (GFR $\left.>90 \mathrm{ml} / \mathrm{min} / 1.73 \mathrm{~m}^{2}\right)$ or slightly reduced (GFR $60-89 \mathrm{ml} / \mathrm{min} / 1.73 \mathrm{~m}^{2}$ ), respectively, with evidence of renal damage (e.g. proteinuria). In CKD stages 3 and 4, functional impairment is moderate (GFR $30-59 \mathrm{ml} / \mathrm{min} / 1.73 \mathrm{~m}^{2}$ ) or severe (GFR $15-29 \mathrm{ml} / \mathrm{min} / 1.73 \mathrm{~m}^{2}$ ), respectively. Finally, CKD stage 5 is defined by kidney failure (GFR $<15 \mathrm{ml} / \mathrm{min}$ / $1.73 \mathrm{~m}^{2}$ ) or dialysis, and is also termed end-stage renal disease (ESRD) [15]. Recently, the Kidney Disease: Improving Global Outcomes (KDIGO) foundation performed a meta-analysis to investigate the relationship of estimated GFR (eGFR) and albuminuria with mortality and kidney outcomes: the results confirmed the current definition for CKD, i.e. GFR $<60 \mathrm{ml} /$ $\mathrm{min} / 1.73 \mathrm{~m}^{2}$ or urinary albumin to creatinine ratio (ACR) $>30 \mathrm{mg} / \mathrm{g}$ [16].

In the last decades, the majority of studies on CKD focused on its most advanced stages (stages 4-5). ESRD patients usually present with many complications, high mortality, strongly reduced quality of life, and high health care expenditures [17,18]. At this stage renal replacement therapy (RRT), consisting in hemodialysis, peritoneal dialysis, hemofiltration, and kidney transplantation, becomes necessary [19].

Unfortunately these interventions are expensive and not always available. Hemodialysis costs amount to 530 Swiss Francs per session [20]. whereas renal transplantation costs are 58,300 Swiss Francs in the first year [21]. Moreover, there is an increasing gap between the number of donors and the number of patients waiting for a kidney: whereas the number of kidney transplantations between 2002 and 2011 slowly increased from 204 to 282 (i.e. $+38 \%$ ), the number of patients on the waiting list increased from 744 to 1,185 (i.e. $+59 \%$ ). In 2009 the mean waiting time for a donor organ was around 700 days [22].

Except for RRT, there is no other treatment for CKD patients with ESRD. Even at early stages, actual treatment options mainly aim to prevent or slow disease progression by controlling risk 
factors such as hypertension, diabetes, and obesity [23]. In short, prevention plays a key role in CKD management.

One of the biggest issues in CKD prevention is actually disease awareness. In the Kidney Early Evaluation Program (KEEP), a community-based screening program, only $10.0 \%$ of the 26,213 participants were aware of suffering from CKD. The proportion in awareness was particularly low for early CKD, with $5.1 \%, 6.3 \%$, and $10.0 \%$ for stages 1 to 3 , respectively. In contrast, almost $40 \%$ of the patients with CKD stage 4 , and $60 \%$ of those with CKD stage 5 were aware of having renal disease [24]. Thus, despite the fact that effective preventive measures exist, many CKD patients remain undiagnosed and untreated. In this regard, family physicians play a fundamental role by timely diagnosis of diabetes mellitus and hypertension in their patients, the latter being the major contributors to GKD. However, screening for signs of renal damage is required, too. Early diagnosis and treatment of CKD and CKD related complications (e.g. anaemia, dyslipidemia, metabolic bone disease, metabolic acidosis, etc.) might prevent or slow the development of further sequelae and delay the requirement for RRT [25,26]. In a large retrospective study including about 12,000 patients with stage 3 or 4 CKD in primary care, the authors reported that CKD management, especially without the involvement of a nephrologist, was not optimal: $72 \%$ of patients with diagnosed CKD lacked annual urine protein testing, 26\% were not receiving appropriate angiotensin blockade, and $20 \%$ were taking potentially harmful drugs [27]. Moreover, whereas annual screening for anaemia was common (80\%), annual testing for metabolic bone disease was less frequent (calcium $56 \%$, vitamin D 26\%, parathyroid hormone 13\%).

One of the first steps to improve CKD management is knowledge about CKD prevalence. Consequently, in the last few years, research has focused on the epidemiology of CKD [28,29]. Supposing that the simplest way to identify CKD is through a family doctor, the aim of this study was to estimate the prevalence of CKD in a primary care setting in Switzerland. The results of this study may provide important information for future national preventive programs, optimizing the resource allocation process. The estimations at national level may improve public awareness for CKD and CKD related diseases.

\section{Materials and Methods}

\section{Study Design and Patient Population}

A cross-sectional, multicentre, non-interventional study was conducted in seven of the 26 Swiss cantons, including all five Swiss cantons with university affiliated medical faculties (i.e. Basel, Bern, Geneva, Vaud, and Zurich), the largest canton in central Switzerland (Lucerne), and the Italian speaking canton of Ticino. The selected cantons were home to nearly $60 \%$ of the entire Swiss population in 2010 and represent all three major language regions in Switzerland (German: Basel, Bern, Lucerne, and Zurich; French: Geneva and Vaud; Italian: Ticino) [30]. Physicians invited to participate in the study were randomly selected from the total pool of general practitioners (GPs) in each canton. Random selection was performed by a computer program generating random numbers. Physicians from 33 offices agreed to participate. The study coordination centre defined the days of patient inclusion by the GPs meeting inclusion criteria (i.e. age $\geq 18$ years and the ability to provide written inform consent). Emergency patients and patients for which the participation in the study might have caused relevant delays in patient management were excluded for ethical reasons. Otherwise, all patients were consecutively included into the study. The study was conducted according to the Declaration of Helsinki (as revised in
2008) and with the International Conference on HarmonizationGood Clinical Practice (ICH-GCP) standards. The study was approved by all seven cantonal ethics committees: Ethikkommission beider Basel (EKBB), Kantonale Ethikkommission Bern (KEK), Commission d'éthique pour la recherche clinique dans le Canton de Genève, Ethikkommission des Kantons Luzern, Comitato etico cantonale del Canton Ticino, Commission cantonale (VD) d'éthique de la recherche sur l'être humain, and Kantonale Ethikkommission (KEK) Zürich.

\section{Measures}

Socio-demographic variables, clinical status and co-morbidities were reported on a questionnaire. Urine and blood samples were sent to a central laboratory for analysis. A spot urine was collected in a Greiner Vacuette tube without preservatives (Greiner Bio One, Krems, Austria), whereas venous blood was collected in Sarstedt Monovette EDTA tubes and in serum tubes containing separation gel (Sarstedt, Sevelen, Switzerland). After serum sample centrifugation, the samples were mailed to the central laboratory (Labormedizinisches Zentrum Dr. Risch) using overnight delivery service by the Swiss Postal Service. Laboratory analysis was performed on the day the samples were received. Laboratory parameters were determined on an Abbott ARCHITECT ci4100 analyzer platform (Abbott, Baar, Switzerland), a Sysmex XT-5000 hematology analyzer (Sysmex Digitana, Horgen, Switzerland), and a Bio-Rad D-10 HPLC system for the determination of glycated haemoglobin (HbAlc; Biorad, Pratteln, Switzerland). The following parameters were measured to assess kidney function and damage: serum and urinary creatinine using the Jaffé method, cystatin $\mathrm{C}$ in the serum and urinary albumin (all from Abbott, Baar, Switzerland). In our hands, the intra-assay coefficient of variation $(\mathrm{CV}$; $\mathrm{n}=20$ ) for creatinine was $1.5 \%$ at $60 \mu \mathrm{mol} / \mathrm{L}, 1.0 \%$ at $168 \mu \mathrm{mol} /$ $\mathrm{L}$, and $0.7 \%$ at $624 \mu \mathrm{mol} / \mathrm{L}$. The respective $\mathrm{CV}$ 's were $1.8 \%$ at $0.7 \mathrm{mg} / \mathrm{L}$ and $2.0 \%$ at $3.5 \mathrm{mg} / \mathrm{L}$ for cystatin $\mathrm{C}$, and $1.6 \%$ at $32.5 \mathrm{mg} / \mathrm{L}, 1.5 \%$ at $119.5 \mathrm{mg} / \mathrm{L}$ for urinary albumin.

\section{Statistical Analysis}

Data were analyzed with IBM SPSS ${ }^{\circledR}$ Statistics 19.0 and Microsoft Office Excel 2007. Chi-square tests and t-tests were used for categorical and continuous variables, respectively. A two-tailed $\mathrm{p}$ value $<0.05$ was considered statistically significant.

The eGFR was calculated with the CKD-EPI equation [31,32]. All patients were stratified into CKD stages using the classification recently proposed by KDIGO [33].

Extrapolation of CKD prevalence in primary care to national level was based first on the 3,769,686 Swiss patients older than 15 years of age who had visited a GP at least once in 2007 (i.e. $62.7 \%$ of the Swiss population $>15$ years), as reported by the Swiss Federal Statistical Office [34]. Secondly, using the percentages calculated in our study sample and adjusting the results for age and gender, the prevalence of CKD patients in primary care in Switzerland was estimated.

Generalized linear models were fitted to control for factors that may be related to reduced eGFR or elevated ACR. In the first model, age, gender, and clinical characteristics of the study population were entered. In the second model, the laboratory parameters were analyzed. All variables showing significant results were used in a third model. The variables confirming significance in the third generalized linear model were finally combined in a simple linear regression analysis. The coefficient of determination ( $\mathrm{R}$ square) and Pearson correlation coefficients were calculated. Significant variables were tested for multicollinearity by calculating the variance inflation factors (VIFs). 


\section{Results}

\section{Socio-demographic and Clinical Characteristics of the Study Population}

Among the 1,000 individuals recruited, 57\% were female, and the mean age was $57 \pm 17$ years. The main socio-demographic and clinical characteristics of the patients according to gender are shown in Table 1. Gender comparisons revealed that males had a significantly higher BMI, higher systolic and diastolic blood pressures, a higher mean arterial pressure, and a lower heart rate. Concerning co-morbidities, males reported a significantly higher prevalence of hypertension, diabetes, and myocardial infarction. Only depression was significantly more frequent among women. No relevant differences were found regarding family history for cardiovascular disease, diabetes or CKD, which were positive in about $30 \%, 20 \%$ and $5-6 \%$ of the patients, respectively.

\section{Laboratory Parameters}

The results of the laboratory analysis showed that mean values of many parameters were significantly different between males and females (i.e. serum creatinine, albumin in the urine, urinary neutrophil gelatinase-associated lipocalin (NGAL), cystatin C, total cholesterol, high-density lipoprotein (HDL), high sensitive troponin, folic acid, ferritin, chloride, inorganic phosphate, HbAlc, alanine and aspartate transaminase, gamma-glutamyl transpeptidase, bilirubin total, and albumin). However, the majority of the laboratory parameters were within normal range for both genders (Table 2). For both genders, elevated values were found for total cholesterol, fasting low-density lipoprotein (LDL), parathyroid hormone (PTH), and glycated hemoglobin (HbAlc). Females showed slightly elevated values of C-reactive protein (CRP) and inorganic phosphate, whereas males had slightly elevated alanine transaminase values.

\section{CKD Prevalence in the Study Population}

Overall, $41.1 \%$ of the patients had normal eGFR and ACR, whereas $35.9 \%$ of the subjects had slightly reduced excretory renal function (eGFR: $60-90 \mathrm{ml} / \mathrm{min} / 1.73 \mathrm{~m}^{2}$ ) with physiological albuminuria based on normal ACR $(<30 \mathrm{mg} / \mathrm{g})$. About one tenth of the patients had a substantially reduced eGFR of $<60 \mathrm{ml} / \mathrm{min} / 1.73 \mathrm{~m}^{2}$, and $17.1 \%$ showed relevant proteinuria (ACR $\geq 30 \mathrm{mg} / \mathrm{g}$ ). Almost one fourth of the analyzed subjects had CKD, i.e. they had either a substantial reduction in renal function or high levels of proteinuria (Table 3). CKD prevalence in our study population was clearly associated with increasing age: below 60 years of age CKD prevalence showed a slow increase (from 7\% to $14 \%$ ). Thereafter it increased faster, reaching $26 \%$ for patients aged $60-74$ years and $52 \%$ for patients over 75 years of age $(\mathrm{p}<0.001 ;$ Figure 1). If compared to patients without renal disease, CKD patients showed a more balanced gender distribution ( $51.3 \%$ vs. $58.3 \%$ females, $\mathrm{p}=0.060)$, but were significantly older $(67 \pm 16$ vs. $53 \pm 16$ years, $p<0.001)$, and had significantly higher BMI (28 \pm 5 vs. $27 \pm 5, p=0.001)$. Moreover they showed a significantly higher prevalence of diabetes $(28.3 \%$ vs. $10.1 \%$, $\mathrm{p}<0.001$ ), hypertension (53.9\% vs. $27.0 \%, \mathrm{p}<0.001)$, myocardial infarction $(8.7 \%$ vs. $3.0 \%, \mathrm{p}<0.001)$, and heart failure $(10.9 \%$ vs. $2.6 \%, \mathrm{p}<0.001)$. No significant differences were found concerning family history of diabetes, cardiovascular diseases, and CKD.

\section{Regression Analyses}

In order to control for factors that may be related to eGFR reduction or to an ACR increase regression analysis was performed. Concerning eGFR, in the first generalized linear model, age $(p<0.001)$, gender $(p<0.001)$, and heart failure $(\mathrm{p}<0.001)$ were significantly and independently correlated with eGFR. In the second model, statistically significant correlations with eGFR were found for cystatin $\mathrm{C}(\mathrm{p}<0.001)$, total cholesterol $(\mathrm{p}<0.001)$, HDL $(\mathrm{p}<0.001)$, high sensitive C-reactive protein

Table 1. Socio-demographic and clinical characteristics of the study population according to gender.

\begin{tabular}{|c|c|c|c|}
\hline \multirow{2}{*}{ Clinical status } & \multirow{2}{*}{$\begin{array}{l}\text { Females } \\
\text { Mean } \pm \text { SD or } \%\end{array}$} & \multirow{2}{*}{$\begin{array}{l}\text { Males } \\
\text { Mean } \pm \text { SD or } \%\end{array}$} & \multirow[t]{2}{*}{$\mathbf{P}$} \\
\hline & & & \\
\hline $\mathrm{N}$ & 567 & 433 & - \\
\hline Age (years) & $56 \pm 18$ & $57 \pm 16$ & 0.155 \\
\hline BMI $\left(\mathrm{kg} / \mathrm{m}^{2}\right)$ & $27 \pm 6$ & $28 \pm 4$ & 0.010 \\
\hline Systolic blood pressure $(\mathrm{mmHg})$ & $133 \pm 20$ & $138 \pm 18$ & $<0.001$ \\
\hline Diastolic blood pressure $(\mathrm{mmHg})$ & $79 \pm 11$ & $83 \pm 13$ & $<0.001$ \\
\hline Mean arterial pressure $(\mathrm{mmHg})$ & $97 \pm 13$ & $101 \pm 13$ & $<0.001$ \\
\hline Pulse pressure (mmHg) & $54 \pm 18$ & $55 \pm 17$ & 0.334 \\
\hline Heart rate (bpm) & $74 \pm 11$ & $71 \pm 12$ & 0.001 \\
\hline Smoker & 18.9 & 16.4 & 0.311 \\
\hline Hypertension & 29.1 & 38.6 & 0.001 \\
\hline Depression & 15.7 & 7.9 & $<0.001$ \\
\hline Diabetes & 12.0 & 17.3 & 0.012 \\
\hline Myocardial infarction & 2.7 & 6.6 & 0.003 \\
\hline Heart failure & 3.5 & 5.8 & 0.062 \\
\hline Family history of Diabetes & 21.9 & 18.8 & 0.133 \\
\hline Cardiovascular disease & 31.4 & 29.9 & 0.221 \\
\hline Chronic kidney disease & 6.6 & 4.5 & 0.109 \\
\hline
\end{tabular}

BMI, body mass index; bpm, beats per minute; $\mathrm{mmHg}$, millimetre of mercury; $\mathrm{N}$, number of subjects; SD, standard deviation.

doi:10.1371/journal.pone.0067848.t001 
Table 2. Laboratory parameters in the recruited patient population.

\begin{tabular}{|c|c|c|c|}
\hline \multirow[t]{2}{*}{ Laboratory parameter } & \multirow{2}{*}{$\begin{array}{l}\text { Females } \\
\text { Mean }[95 \% \mathrm{Cl}]\end{array}$} & \multirow{2}{*}{$\frac{\text { Males }}{\text { Mean }[95 \% \mathrm{Cl}]}$} & \multirow[t]{2}{*}{$\mathbf{P}$} \\
\hline & & & \\
\hline \multicolumn{4}{|l|}{ Kidney } \\
\hline Serum creatinine $(\mu \mathrm{mol} / \mathrm{l})$ & $71.4[69.8-73.0]$ & $87.7[85.1-90.3]$ & $<0.001$ \\
\hline Albumin in urine $(\mathrm{mg} / \mathrm{l})$ & $19.5[16.0-22.9]$ & $53.9[40.3-67.5]$ & $<0.001$ \\
\hline Urinary NGAL (ng/l) & $64.9[46.8-83.0]$ & $29.1[23.9-34.4]$ & 0.001 \\
\hline Cystatin C (mg/l) & $0.81[0.79-0.83]$ & $0.86[0.83-0.89]$ & 0.004 \\
\hline \multicolumn{4}{|l|}{ Lipids } \\
\hline Total cholesterol (mmol/l) & $5.64[5.53-5.74]$ & $5.39[5.28-5.49]$ & 0.001 \\
\hline $\mathrm{HDL}(\mathrm{mmol} / \mathrm{l})$ & $1.66[1.62-1.69]$ & $1.35[1.32-1.38]$ & $<0.001$ \\
\hline Fasting LDL (mmol) * & $3.36[3.13-3.60]$ & $3.29[3.09-3.49]$ & 0.636 \\
\hline Fasting triglycerides $(\mathrm{mmol} / \mathrm{l}){ }^{*}$ & $1.45[1.32-1.58]$ & $1.70[1.46-1.95]$ & 0.066 \\
\hline \multicolumn{4}{|l|}{ Inflammation } \\
\hline High sensitive CRP (mg/l) & $5.24[4.47-6.00]$ & $4.33[3.42-5.24]$ & 0.134 \\
\hline \multicolumn{4}{|l|}{ Heart disease } \\
\hline BNP (pg/ml) & $53.75[47.7-59.8]$ & $61.91[46.5-77.3]$ & 0.289 \\
\hline High sensitive troponin (ng/l) & $1.94[1.45-2.43]$ & $3.74[2.74-4.75]$ & 0.001 \\
\hline \multicolumn{4}{|l|}{ Nutritional parameters } \\
\hline Vitamin B12 (pg/ml) & $292.6[272.2-313.0]$ & $289.8[265.2-314.3]$ & 0.858 \\
\hline Folic acid $(\mathrm{mg} / \mathrm{ml})$ & $19.5[18.6-20.4]$ & 16.8 [15.9-17.6] & $<0.001$ \\
\hline Ferritin (ng/ml) & $92.9[81.5-104.4]$ & $194.3[177.9-210.7]$ & $<0.001$ \\
\hline \multicolumn{4}{|l|}{ Electrolytes } \\
\hline Sodium (mmol/l) & $141.8[141.5-142.1]$ & $141.7[141.3-142.0]$ & 0.580 \\
\hline Potassium $(\mathrm{mmol} / \mathrm{l})$ & $4.82[4.72-4.92]$ & $4.75[4.65-4.85]$ & 0.330 \\
\hline Chloride (mmol/l) & $103.3[103.0-103.7]$ & $102.6[102.2-103.0]$ & 0.004 \\
\hline \multicolumn{4}{|l|}{ Calcium phosphate metabolism } \\
\hline Parathormone (pmol/l) & $7.40[7.01-7.79]$ & $7.03[6.54-7.52]$ & 0.237 \\
\hline Calcium (mmol/l) & $2.40[2.39-2.41]$ & $2.41[2.39-2.42]$ & 0.461 \\
\hline Inorganic phosphate $(\mathrm{mmol} / \mathrm{l})$ & $1.70[1.61-1.79]$ & $1.51[1.41-1.62]$ & 0.009 \\
\hline \multicolumn{4}{|l|}{ Diabetes mellitus } \\
\hline HbA1c (\%) & $5.93[5.85-6.02]$ & $6.09[5.98-6.19]$ & 0.023 \\
\hline \multicolumn{4}{|l|}{ Liver function panel } \\
\hline Alanine transaminase $(\mathrm{U} / \mathrm{l})$ & $26.2[24.7-27.7]$ & $39.3[36.7-41.8]$ & $<0.001$ \\
\hline Aspartate transaminase $(\mathrm{U} / \mathrm{I})$ & $26.7[25.6-27.8]$ & $31.7[30.4-33.0]$ & $<0.001$ \\
\hline Gamma-glutamyl transpeptidase (U/I) & $30.3[26.4-34.1]$ & $53.9[47.0-60.7]$ & $<0.001$ \\
\hline Alkaline phosphatase (U/I) & $72.9[71.0-74.9]$ & $72.3[69.9-74.8]$ & 0.701 \\
\hline Bilirubin total $(\mu \mathrm{mol} / \mathrm{l})$ & $9.0[8.6-9.4]$ & $12.1[11.5-12.7]$ & $<0.001$ \\
\hline Albumin $(g / l)$ & $44.1[43.9-44.3]$ & $45.0[44.3-44.7]$ & $<0.001$ \\
\hline
\end{tabular}

BNP, brain natriuretic peptide; $\mathrm{Cl}$, confidence interval; CRP, C-reactive protein; HbA1c, glycated haemoglobin A1c; HDL, high-density lipoprotein; LDL, low-density lipoprotein; NGAL, neutrophil gelatinase-associated lipocalin. * $\mathrm{N}=107$ for females and 100 for males.

doi:10.1371/journal.pone.0067848.t002

(CRP, $\mathrm{p}=0.033)$, brain natriuretic peptide $(\mathrm{BNP}, \mathrm{p}=0.007)$, folic acid $(p=0.001)$, sodium $(p<0.001)$, inorganic phosphate $(\mathrm{p}<0.001)$, HbAlc $(\mathrm{p}<0.001)$, alanine transaminase $(\mathrm{p}=0.001)$, and albumin $(p=0.024)$. In the third model combining all significant factors, gender, age, cystatin $\mathrm{C}$, HDL, BNP, sodium, inorganic phosphate, $\mathrm{HbAlc}$, and albumin remained significantly correlated with eGFR. The combination of the variables from the third model in a simple linear regression model confirmed a strong relationship with the eGFR $(\mathrm{R}=0.839$, adjusted $\mathrm{R}$ square $=0.701)$. Particularly strong correlations were found for age (Pearson correlation coefficient $\rho=-0.648$ ) and cystatin c $(\rho=-0.667)$. No multicollinearity problems were found (Table 4$)$.

For ACR, the first model showed significant correlations with gender $(p=0.019)$, age $(p=0.036)$, heart rate $(p=0.021)$, diabetes $(p=0.001)$, and heart failure $(p=0.016)$. In the second model, significant results were found for urinary NGAL $(p=0.001)$, cystatin C $(p=0.001)$, BNP $(p<0.001)$, and HbAlc $(p<0.001)$. After combining all significant factors in a third model, gender, heart rate, diabetes, heart failure, urinary NGAL, cystatin C, BNP, and $\mathrm{HbAlc}$ remained significantly and independently correlated with ACR. The combination of these variables in a linear 
Table 3. Chronic kidney disease stages, as proposed in the KDIGO classification.

\begin{tabular}{|c|c|c|c|c|}
\hline \multirow[b]{2}{*}{ EGFR Stage } & \multicolumn{3}{|c|}{ Albuminuria stage } & \multirow[b]{2}{*}{ All } \\
\hline & A1 (<10 mg/g) & A1 $(10-29 \mathrm{mg} / \mathrm{g})$ & A2-3 ( $\geq 30 \mathrm{mg} / \mathrm{g})$ & \\
\hline$\left(\mathrm{ml} / \mathrm{min} / 1.73 \mathrm{~m}^{2}\right)$ & N (\%) & N (\%) & N (\%) & N (\%) \\
\hline G1 (>105) & $129(12.9)$ & $60(6.0)$ & $27(2.7)$ & $216(21.6)$ \\
\hline G1 (90-105) & $156(15.6)$ & $66(6.6)$ & $33(3.3)$ & 255 \\
\hline G2 (75-89) & $144(14.4)$ & $99(9.9)$ & $33(3.3)$ & $276(27.6)$ \\
\hline G2 (60-74) & $59(5.9)$ & $57(5.7)$ & $33(3.3)$ & $149(14.9)$ \\
\hline G3-5 $(<60)$ & $25(2.5)$ & $34(3.4)$ & $45(4.5)$ & $104(10.4)$ \\
\hline All & $513(51.3)$ & $316(31.6)$ & $171(17.1)$ & $1000(100)$ \\
\hline
\end{tabular}

EGFR, estimated glomerular filtration rate (calculated using the CKD-EPI formula); KDIGO, Kidney Disease, Improving Global Outcomes.

doi:10.1371/journal.pone.0067848.t003

regression analysis showed a weak relationship $(\mathrm{R}=0.439$, adjusted $\mathrm{R}$ square $=0.186$ ). The highest Pearson correlation coefficients were found for BNP $(\rho=0.322)$, cystatin $c$ $(\rho=0.247)$, and HbAlc $(\rho=0.215)$. Again, no multicollinearity problems were found (Table 4).

\section{Extrapolation to National Level}

In the extrapolation of CKD prevalence to the national level we made the assumption, that about $60 \%$ of the Swiss population visit a primary care physician at least once yearly (Table 5). Of those, almost $19 \%$ (i.e. ca 700,000 patients, $11.4 \%$ of the subjects older than 15 years) may suffer from CKD, having a substantially reduced eGFR $\left(<60 \mathrm{ml} / \mathrm{min} / 1.73 \mathrm{~m}^{2}\right)$ and/or relevant proteinuria $($ ACR $\geq 30 \mathrm{mg} / \mathrm{g})$.

\section{Discussion}

This study shows that CKD prevalence and/or renal function impairment in the general Swiss population is considerably high. In our sample only about $40 \%$ of the patients had a normal renal function with an eGFR $\geq 90 \mathrm{ml} / \mathrm{min} / 1.73 \mathrm{~m}^{2}$ and an ACR $<30 \mathrm{mg} / \mathrm{g}$. About one third of the subjects showed slightly reduced filtration rate (eGFR $60-89 \mathrm{ml} / \mathrm{min} / 1.73 \mathrm{~m}^{2}$ ) with physiological ACR, whereas $23 \%$ of the patients fulfilled the criteria of CKD (i.e. eGFR $<60 \mathrm{ml} / \mathrm{min} / 1.73 \mathrm{~m}^{2}$ and/or ACR $>30 \mathrm{mg} / \mathrm{g}$ ), as defined by KDIGO [33].

Our study sample, which was derived from a primary care population, is nevertheless comparable to that of the Swiss Survey on Salt, and, to some extent, to the general Swiss population. In the Swiss Survey on Salt, a prospective, nationwide survey conducted in 2010-2011 with a random sample of 1,377 subjects, the mean age was 47.3 years, with $51.2 \%$ females, $17.3 \%$ current smokers, a mean BMI of $25.1 \mathrm{~kg} / \mathrm{m}^{2}$, and a $25.6 \%$ prevalence of hypertension (32.3\% and $19.1 \%$ for male and females respectively) [35]. At national level, the Swiss Federal Statistical Office reports the mean age of the adult patients visiting at least once a primary care physician in 2007 being 48.7 years (48.9\% males) [34]. Moreover, the following prevalence were estimated within the Swiss population in 2007:27.9\% smokers $(32.3 \%$ males, $23.6 \%$ females), $15.0 \%$ hypertension $(15.9 \%, 14.1 \%), 8.0 \%$ depression $(6.2 \%, 9.8 \%), 3.0 \%$ diabetes $(3.5 \%, 2.5 \%)$, and $2.1 \%$ myocardial infarction $(3.1 \%, 1.2 \%)$ [36].

By extrapolation to national level, and after adjustment for age and gender, the percentage of patients in primary care that may have CKD is high, with almost $19 \%$ of the primary care population having substantially reduced renal function and/or

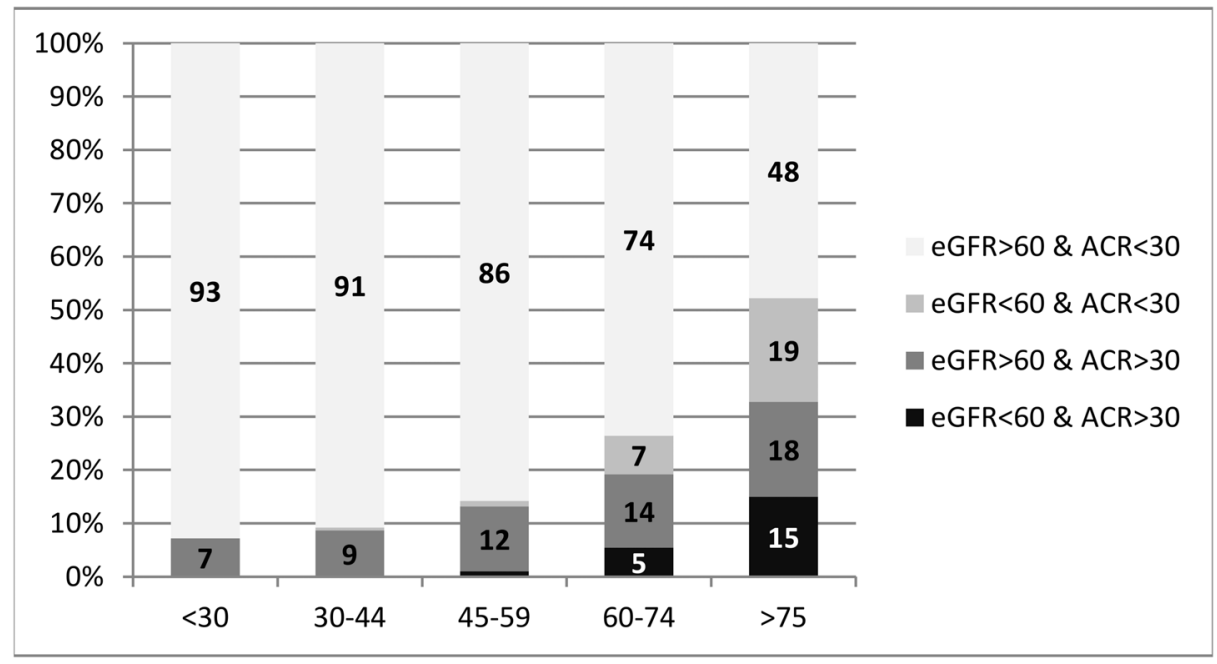

Figure 1. Percentage of patients with reduced eGFR and/or elevated ACR for different age groups. ACR, albumin-creatinine ratio (given as $\mathrm{mg} / \mathrm{mmol}$ ); eGFR, estimated glomerular filtration rate (given as $\mathrm{ml} / \mathrm{min} / 1.73 \mathrm{~m}^{2}$ ).

doi:10.1371/journal.pone.0067848.g001 
Table 4. Spearman correlation coefficients $(\rho)$ between eGFR/ACR and the significantly correlated variables.

\begin{tabular}{|c|c|c|c|}
\hline \multirow{2}{*}{$\begin{array}{l}\text { eGFR } \\
\text { Variable }\end{array}$} & \multirow[b]{2}{*}{$\rho$} & \multirow[b]{2}{*}{$\mathbf{P}$} & \multirow[b]{2}{*}{ VIF } \\
\hline & & & \\
\hline Age & -0.648 & $<0.001$ & 1.517 \\
\hline Gender & 0.089 & $<0.001$ & 1.231 \\
\hline Cystatin C & -0.667 & $<0.001$ & 1.460 \\
\hline HDL & -0.043 & 0.012 & 1.253 \\
\hline BNP & -0.298 & 0.015 & 1.151 \\
\hline Sodium & -0.156 & $<0.001$ & 1.111 \\
\hline Inorganic Phosphate & -0.256 & $<0.001$ & 1.076 \\
\hline $\mathrm{HbA1c}$ & -0.229 & 0.017 & 1.145 \\
\hline Albumin & 0.128 & 0.003 & 1.121 \\
\hline \multicolumn{4}{|c|}{$R=0.839$, adjusted $R$ square $=0.701$} \\
\hline \multicolumn{4}{|l|}{ ACR } \\
\hline Variable & $\rho$ & $\mathbf{P}$ & VIF \\
\hline Gender & 0.102 & 0.001 & 1.040 \\
\hline Heart rate & 0.098 & $<0.001$ & 1.023 \\
\hline Diabetes & 0.169 & 0.049 & 1.545 \\
\hline Heart failure & 0.121 & 0.028 & 1.270 \\
\hline Urinary NGAL & 0.154 & $<0.001$ & 1.027 \\
\hline Cystatin C & 0.247 & $<0.001$ & 1.213 \\
\hline BNP & 0.322 & $<0.001$ & 1.282 \\
\hline $\mathrm{HbA1c}$ & 0.215 & 0.001 & 1.588 \\
\hline
\end{tabular}

$R=0.439$, adjusted $R$ square $=0.186$

BNP, brain natriuretic peptide; $\mathrm{HbA1c}$, glycated haemoglobin $\mathrm{A} 1 \mathrm{c} ; \mathrm{HDL}$, highdensity lipoprotein; NGAL, neutrophil gelatinase-associated lipocalin; VIF, variance inflation factor.

doi:10.1371/journal.pone.0067848.t004

relevant proteinuria. These results, again, are comparable to those found in the Swiss Survey on Salt, with a reported prevalence of about $7.7 \%$ of the included population for CKD stage 3 or higher. In our study, $10.4 \%$ of the patients had an eGFR $<60 \mathrm{ml} / \mathrm{min} /$ $1.73 \mathrm{~m}^{2}$. The difference of almost $3 \%$ may be explained by diverse recruitment strategies: whereas in our study the subjects were recruited in a primary care setting, in the Swiss Survey on Salt, the participants were recruited using a list of randomly selected households from the major Swiss telecommunication company's home phone directory. For each household, one person was randomly selected and invited to participate in the study. It is reasonable to suppose that this sample was not only younger if compared to our study population, but also healthier and therefore less likely to suffer from CKD and other diseases. In the US National Health and Nutrition Examination Survey (NHANES) 1999-2006, a representative cross-sectional national survey, 9,536 participants were interviewed at home and/or received standardized medical examination in mobile study centers [37]. The prevalence of CKD was $18.3 \%$ (9.1\% for CKD stage $3-5)$. Again, these rates are comparable to our results.

The generalized linear regression models showed that both eGFR and ACR are strictly correlated with gender, cystatin C, $\mathrm{BNP}$, and HbAlc. It is interesting to note that whereas eGFR was correlated with age and several blood/urine parameters (e.g. sodium, HDL, inorganic phosphate), ACR was age independent and directly correlated to diabetes and heart failure. These results emphasize the importance of ACR as screening and prognostic factor for young patients and for patients with diabetes and/or heart failure. For example, in the Kidney Early Evaluation Program (KEEP) Annual Data Report 2007, it has been shown that ACR is the predominant positive screening test for younger age groups: in KEEP, about $80 \%$ and $60 \%$ of the CKD patients aged 18-30 and 31-45 years, respectively, showed elevated ACR with normal eGFR. Even higher percentages were found in the NHANES cohort from 1999-2004 [38]. In a case control study including non-diabetic and non-hypertensive patients it has been found that elevated ACR was significantly higher in patients with systolic heart failure, if compared to matched controls [39].

Some limitations of the study have to be considered. Firstly, screened subjects were volunteers and therefore not necessarily representative for the overall primary care population in Switzerland. In this study, emergency patients were excluded for ethical reasons. Moreover, it is possible that patients visiting the GP with a relatively serious/painful disease tend to refuse to participate. This may have resulted in an underestimation of the true CKD prevalence. A second limitation concerns the use of a creatinine based estimation for renal filtration function. In the last years, many formulas have been developed to calculate eGFR: the Modification of Diet in Renal Disease (MDRD) formula, the Mayo Quadratic formula, and the CKD-EPI formula [32,40-43].

Table 5. Chronic kidney disease prevalence in primary care.

\begin{tabular}{llll}
\hline Age group & $\mathbf{N}$ in $\mathbf{~ C H}$ & With at least 1 GP visit & CKD (eGFR <60 or ACR $\geq 30$ ) \\
\hline $15-24$ & 944947 & 530348 & 39758 \\
$25-34$ & 948865 & 483491 & 54666 \\
$35-44$ & 1217255 & 638988 & 46409 \\
$45-54$ & 1064447 & 610875 & 84456 \\
$55-64$ & 895114 & 601024 & 113482 \\
$65-74$ & 610651 & 475489 & 138218 \\
$75+$ & 505433 & 429471 & 226665 \\
Total & 6186712 & 3769686 & 703655 \\
$\%$ & $100.0 \%$ & $60.9 \%$ & $11.4 \%$ \\
\hline
\end{tabular}

$\mathrm{ACR}$, albumin-creatinine ratio (given as $\mathrm{mg} / \mathrm{mmol}$ ); $\mathrm{CH}$, Switzerland; $\mathrm{CKD}$, chronic kidney disease; eGFR, estimated glomerular filtration rate (given as $\mathrm{ml} / \mathrm{min} / 1.73 \mathrm{~m}{ }^{2}$ ); GP, general practitioners.

doi:10.1371/journal.pone.0067848.t005 
Actually, the CKD-EPI equation seems to be the more precise formula for primary care patients [31,44-47]. However, it is not yet recognized as the gold standard. The third limitation regards the cross-sectional nature of the study, in which only one single measurement per patient has been performed. The absence of a repeated eGFR assessment may potentially have resulted in misclassification of some patients (e.g. of individuals with acute changes in kidney function). In a study conducted by Bottomley et al., the potential overestimation of CKD prevalence after a single eGFR measurement was investigated in 512 factory workers (60.9\% males, mean age 43 years) [48]. The repeat analyses conducted 3 months after baseline evaluation revealed no significant change in the mean eGFR. However, $21 \%$ of the retested individuals had a change in their category of CKD stage and initial proteinuria was reproducible in only $48 \%$ of the cases. In a larger community based study including more than 20,000 patients over 45 years of age, Weiner et al. found that in $76.2 \%$ of the patients with initial eGFR $<60 \mathrm{ml} / \mathrm{min} / 1.73 \mathrm{~m}^{2}$ and in $83.6 \%$ of those with eGFR $\geq 60 \mathrm{ml} / \mathrm{min} / 1.73 \mathrm{~m}^{2}$ a stable level of renal filtration function was found at follow up [12]. In this report, the study groups had a mean age of 73.4 and 59.9 years, respectively ( $55 \%$ females in both groups) and the follow-up was performed about 3 years after the baseline visit. In these studies, the MDRD estimating equation was used, and the participant's characteristics were clearly different from our trial. However, the results emphasize the potential of misclassification related to a cross-sectional design. Therefore, it would have been preferable to conduct a longitudinal study with multiple measurements over time to confirm and to adjust the estimated prevalence of CKD and ACR. Moreover, our study excluded paediatric patients, what confines our conclusions to adults. Beside the intrinsic limitations of a cross-sectional design, it is important to remember that the decline of eGFR with ageing is a sign of physiological senescence. With increasing age and consequent decline in muscle mass there is a consecutive reduction in creatinine generation. In the Nijmegen Biomedical Study including about 6,000 apparently healthy persons aged 18-90 years, the eGFR declined approximately $0.4 \mathrm{ml} / \mathrm{min} / 1.73 \mathrm{~m}^{2}$ per year [49]. Moreover, an eGFR of $60 \mathrm{ml} / \mathrm{min} / 1.73 \mathrm{~m}^{2}$ was within the $25^{\text {th }}$ and $50^{\text {th }}$ percentile for men and women $>65$ years. In another study including more than 10,000 individuals 66 years of age or older, eGFR reductions of $0.8-1.4$ and $2.1-2.7 \mathrm{ml} / \mathrm{min} / 1.73 \mathrm{~m}^{2}$ per year were reported for non-diabetic and diabetic subjects, respectively [50]. These data emphasize that a low eGFR in elderly subjects does not necessarily imply that they have kidney disease. Unfortunately, the current NKF-CKD classification does not take into account these aspects. In general, for people with eGFR $<60 \mathrm{ml} / \mathrm{min} / 1.73 \mathrm{~m}^{2}$ or ACR

\section{References}

1. Eknoyan G, Lameire N, Barsoum R, Eckardt KU, Levin A, et al. (2004) The burden of kidney disease: improving global outcomes. Kidney international 66 : 1310-1314.

2. Thorp ML, Eastman L, Smith DH, Johnson ES (2006) Managing the burden of chronic kidney disease. Dis Manag 9: 115-121.

3. Al-Aly Z, Zeringue A, Fu J, Rauchman MI, McDonald JR, et al. Rate of kidney function decline associates with mortality. J Am Soc Nephrol 21: 1961-1969.

4. Chen YC, Su YC, Lee CC, Huang YS, Hwang SJ Chronic kidney disease itself is a causal risk factor for stroke beyond traditional cardiovascular risk factors: a nationwide cohort study in Taiwan. PloS one 7: e36332.

5. Culleton BF, Larson MG, Wilson PW, Evans JC, Parfrey PS, et al. (1999) Cardiovascular disease and mortality in a community-based cohort with mild renal insufficiency. Kidney international 56: 2214-2219.

6. Go AS, Chertow GM, Fan D, McCulloch CE, Hsu CY (2004) Chronic kidney disease and the risks of death, cardiovascular events, and hospitalization. The New England journal of medicine 351: 1296-1305.

7. Hallan SI, Matsushita K, Sang Y, Mahmoodi BK, Black C, et al. Age and association of kidney measures with mortality and end-stage renal disease. Jama 308: 2349-2360.
$>30 \mathrm{mg} / \mathrm{g}$ (i.e. a suspected CKD) further tests should be performed to determine the type and duration of kidney disease. If the duration is $>3$ months, CKD is formally established. For elderly patients with slight to moderate reduction of renal function it is particularly important to monitor for rapid progression, defined as a sustained decline in eGFR of more than $5 \mathrm{ml} / \mathrm{min} /$ $1.73 \mathrm{~m}^{2}$ per year [51]. Moreover, some studies have shown that decreased eGFR is independently associated with increased risk of cardiovascular diseases or death [52]. Therefore, a rapid decline in renal function may necessitate an adaptation in treatment strategy. Finally, it is important to note that the majority of previously diagnosed CKD patients, especially those with severe CKD stages requiring dialysis, are usually seen by nephrologists. Therefore, this study should be considered as representative only for adult patients in a primary care setting.

In summary, CKD prevalence in a primary care population in Switzerland is high. The growing proportion of elderly people among the Swiss population and the increasing prevalence of many risk factors will result in an increase of CKD prevalence over the next decades. Implementation of prevention and screening programs will be crucial in the managing strategies of many healthcare systems, especially in western countries. In addition, overcoming the lack of CKD awareness must become part of future strategies. Unlike the United States, where educational efforts have been made to increase CKD awareness in the general population (e.g. the formation of the National Kidney Disease Education Program by the National Institutes of Health), [53] in Switzerland and in many other central European countries, CKD is still an underestimated disease [30]. This study, providing new information on CKD prevalence, may represent a first important step towards challenging this issue. Future steps will be to evaluate the actual burden of CKD, to investigate the prevalence of CKD in an inpatient setting, to model possible trends, and to provide suggestions to avoid uncontrolled growth of the CKD population.

\section{Acknowledgments}

We thank Carmel Froidevaux-Walz, Marcin Papka, and Franck Flahaut for technical assistance. The contribution of Marcel Tanner (University of Basel) as a supervisor of the $\mathrm{PhD}$ Thesis of $\mathrm{YT}$ is also gratefully acknowledged.

\section{Author Contributions}

Conceived and designed the experiments: YT LR TS PA. Performed the experiments: YT LR. Analyzed the data: YT. Contributed reagents/ materials/analysis tools: LR. Wrote the paper: YT LR TS PA.

8. McCullough PA, Li S, Jurkovitz CT, Stevens L, Collins AJ, et al. (2008) Chronic kidney disease, prevalence of premature cardiovascular disease, and relationship to short-term mortality. American heart journal 156: 277-283.

9. Roderick PJ, Atkins RJ, Smeeth L, Mylne A, Nitsch DD, et al. (2009) CKD and mortality risk in older people: a community-based population study in the United Kingdom. Am J Kidney Dis 53: 950-960.

10. Ryan TP, Fisher SG, Elder JL, Winters PC, Beckett W, et al. (2009) Increased cardiovascular risk associated with reduced kidney function. American journal of nephrology 29: 620-625.

11. Wang HE, Gamboa C, Warnock DG, Muntner P Chronic kidney disease and risk of death from infection. American journal of nephrology 34: 330-336.

12. Weiner DE, Krassilnikova M, Tighiouart H, Salem DN, Levey AS, et al. (2009) CKD classification based on estimated GFR over three years and subsequent cardiac and mortality outcomes: a cohort study. BMC nephrology 10: 26.

13. Ting SM, Nair H, Ching I, Taheri S, Dassupta I (2009) Overweight, obesity and chronic kidney disease. Nephron 112: c121-127; discussion c127.

14. Stevens LA, Viswanathan G, Weiner DE Chronic kidney disease and end-stage renal disease in the elderly population: current prevalence, future projections, and clinical significance. Advances in chronic kidney disease 17: 293-301. 
15. Levey AS, Eckardt KU, Tsukamoto Y, Levin A, Coresh J, et al. (2005) Definition and classification of chronic kidney disease: a position statement from Kidney Disease: Improving Global Outcomes (KDIGO). Kidney international 67: 2089-2100.

16. Levey AS, de Jong PE, Coresh J, El Nahas M, Astor BC, et al. The definition, classification, and prognosis of chronic kidney disease: a KDIGO Controversies Conference report. Kidney international 80: 17-28.

17. Mucsi I, Kovacs AZ, Molnar MZ, Novak M (2008) Co-morbidity and quality of life in chronic kidney disease patients. Journal of nephrology 21 Suppl 13: S84 91.

18. Powe NR, Plantinga L, Saran R (2009) Public health surveillance of CKD: principles, steps, and challenges. Am J Kidney Dis 53: S37-45.

19. Locatelli F, Del Vecchio L, Pozzoni P, Manzoni C (2006) Nephrology: main advances in the last 40 years. Journal of nephrology 19: 6-11.

20. Bommer J (2002) Prevalence and socio-economic aspects of chronic kidney disease. Nephrol Dial Transplant 17 Suppl 11: 8-12.

21. Swiss Federal Office of Public Health (FOPH), Kosten der Transplantationsmedizin. http://www.bag.admin.ch/transplantation/00692/02582/03136/ index.html?lang = de. Accessed 03 May 2013.

22. Damman K, van Veldhuisen DJ, Navis G, Voors AA, Hillege HL (2008) Urinary neutrophil gelatinase associated lipocalin (NGAL), a marker of tubular damage, is increased in patients with chronic heart failure. European journal of heart failure 10: 997-1000.

23. White SL, Cass A, Atkins RC, Chadban SJ (2005) Chronic kidney disease in the general population. Advances in chronic kidney disease 12: 5-13.

24. Kurella Tamura M, Anand S, Li S, Chen SC, Whaley-Connell AT, et al. Comparison of CKD awareness in a screening population using the Modification of Diet in Renal Disease (MDRD) study and CKD Epidemiology Collaboration (CKD-EPI) equations. Am J Kidney Dis 57: S17-23.

25. Murphree DD, Thelen SM Chronic kidney disease in primary care. J Am Board Fam Med 23: 542-550.

26. Levin A, Hemmelgarn B, Culleton B, Tobe S, McFarlane P, et al. (2008) Guidelines for the management of chronic kidney disease. Cmaj 179: 1154 1162.

27. Allen AS, Forman JP, Orav EJ, Bates DW, Denker BM, et al. Primary care management of chronic kidney disease. Journal of general internal medicine 26 : 386-392.

28. Whaley-Connell AT, Sowers JR, Stevens LA, McFarlane SI, Shlipak MG, et al. (2008) CKD in the United States: Kidney Early Evaluation Program (KEEP) and National Health and Nutrition Examination Survey (NHANES) 19992004. Am J Kidney Dis 51: S13-20.

29. Zhang QL, Rothenbacher D (2008) Prevalence of chronic kidney disease in population-based studies: systematic review. BMC public health 8: 117

30. Coresh J, Astor BC, Greene T, Eknoyan G, Levey AS (2003) Prevalence of chronic kidney disease and decreased kidney function in the adult US population: Third National Health and Nutrition Examination Survey. Am J Kidney Dis 41: 1-12.

31. Levey AS, Stevens LA Estimating GFR using the CKD Epidemiology Collaboration (CKD-EPI) creatinine equation: more accurate GFR estimates, lower CKD prevalence estimates, and better risk predictions. Am J Kidney Dis 55: 622-627.

32. Levey AS, Stevens LA, Schmid CH, Zhang YL, Castro AF, 3rd, et al. (2009) A new equation to estimate glomerular filtration rate. Annals of internal medicine 150: 604-612.

33. Levey AS, Tangri N, Stevens LA Classification of chronic kidney disease: a step forward. Annals of internal medicine 154: 65-67.

34. Selvin E, Kottgen A, Coresh J (2009) Kidney function estimated from serum creatinine and cystatin C and peripheral arterial disease in NHANES 19992002. European heart journal 30: 1918-1925.

35. Forni V, Glatz N, Conen D, Stettler H, Paccaud F, et al. (2011) Prevalence of Chronic Kidney Disease in the Population-Based Swiss Survey on Salt. Swiss med wkly (Suppl 191): 21S

36. Szewczyk M, Wielkoszynski T, Zakliczynski M, Zembala M (2009) Plasma neutrophil gelatinase-associated lipocalin (NGAL) correlations with cystatin $\mathrm{C}$, serum creatinine, and glomerular filtration rate in patients after heart and lung transplantation. Transplantation proceedings 41: 3242-3243.

37. Whaley-Connell A, Sowers JR, McCullough PA, Roberts T, McFarlane SI, et al. (2009) Diabetes mellitus and CKD awareness: the Kidney Early Evaluation Program (KEEP) and National Health and Nutrition Examination Survey (NHANES). Am J Kidney Dis 53: S11-21.

38. McCullough PA, Li S, Jurkovitz CT, Stevens LA, Wang C, et al. (2008) CKD and cardiovascular disease in screened high-risk volunteer and general populations: the Kidney Early Evaluation Program (KEEP) and National Health and Nutrition Examination Survey (NHANES) 1999-2004. Am J Kidney Dis 51: S38-45.

39. Figueiredo EL, Leao FV, Oliveira LV, Moreira MC, Figueiredo AF (2008) Microalbuminuria in nondiabetic and nonhypertensive systolic heart failure patients. Congestive heart failure (Greenwich, Conn 14: 234-238.

40. Levey AS, Bosch JP, Lewis JB, Greene T, Rogers N, et al. (1999) A more accurate method to estimate glomerular filtration rate from serum creatinine: a new prediction equation. Modification of Diet in Renal Disease Study Group. Annals of internal medicine 130: 461-470.

41. Risch L, Saely CH, Neyer U, Hoefle G, Gouya G, et al. (2007) Prevalence of decreased glomerular filtration rate in patients seeking non-nephrological medical care-an evaluation using IDMS-traceable creatinine based MDRD as well as Mayo Clinic quadratic equation estimates. Clinica chimica acta; international journal of clinical chemistry 378: 71-77.

42. Rule AD, Larson TS, Bergstralh EJ, Slezak JM, Jacobsen SJ, et al. (2004) Using serum creatinine to estimate glomerular filtration rate: accuracy in good health and in chronic kidney disease. Annals of internal medicine 141: 929-937.

43. Rigalleau V, Lasseur C, Raffaitin C, Perlemoine C, Barthe N, et al. (2007) The Mayo Clinic quadratic equation improves the prediction of glomerular filtration rate in diabetic subjects. Nephrol Dial Transplant 22: 813-818.

44. Stevens LA, Li S, Kurella Tamura M, Chen SC, Vassalotti JA, et al. Comparison of the CKD Epidemiology Collaboration (CKD-EPI) and Modification of Diet in Renal Disease (MDRD) study equations: risk factors for and complications of CKD and mortality in the Kidney Early Evaluation Program (KEEP). Am J Kidney Dis 57: S9-16.

45. Matsushita K, Tonelli M, Lloyd A, Levey AS, Coresh J, et al. Clinical Risk Implications of the CKD Epidemiology Collaboration (CKD-EPI) Equation Compared With the Modification of Diet in Renal Disease (MDRD) Study Equation for Estimated GFR. Am J Kidney Dis.

46. Matsushita K, Mahmoodi BK, Woodward M, Emberson JR, Jafar TH, et al. Comparison of risk prediction using the CKD-EPI equation and the MDRD study equation for estimated glomerular filtration rate. Jama 307: 1941-1951.

47. Giavarina D, Cruz DN, Soffiati G, Ronco C Comparison of estimated glomerular filtration rate (eGFR) using the MDRD and CKD-EPI equations for CKD screening in a large population. Clinical nephrology 74: 358-363.

48. Bottomley MJ, Kalachik A, Mevada C, Brook MO, James T, et al. Single estimated glomerular filtration rate and albuminuria measurement substantially overestimates prevalence of chronic kidney disease. Nephron 117: c348-352.

49. Wetzels JF, Kiemeney LA, Swinkels DW, Willems HL, den Heijer M (2007) Age- and gender-specific reference values of estimated GFR in Caucasians: the Nijmegen Biomedical Study. Kidney Int 72: 632-637.

50. Hemmelgarn BR, Zhang J, Manns BJ, Tonelli M, Larsen E, et al. (2006) Progression of kidney dysfunction in the community-dwelling elderly. Kidney Int 69: 2155-2161.

51. Haase M, Bellomo R, Devarajan P, Schlattmann P, Haase-Fielitz A (2009) Accuracy of neutrophil gelatinase-associated lipocalin (NGAL) in diagnosis and prognosis in acute kidney injury: a systematic review and meta-analysis. Am J Kidney Dis 54: 1012-1024.

52. O'Hare AM, Bertenthal D, Covinsky KE, Landefeld CS, Sen S, et al. (2006) Mortality risk stratification in chronic kidney disease: one size for all ages? J Am Soc Nephrol 17: 846-853.

53. Smith DH, Gullion CM, Nichols G, Keith DS, Brown JB (2004) Cost of medical care for chronic kidney disease and comorbidity among enrollees in a large HMO population. J Am Soc Nephrol 15: 1300-1306. 